\title{
VREDNOVANJE UTICAJA TC PROMENADA NA USLOVE ODVIJANJA SAOBRAĆAJA NA OKOLNIM RASKRSNICAMA
}

\section{IMPACT EVALUATION OF SC PROMENADA TO THE TRAFFIC CONDITIONS AT THE SURROUNDING INTERSECTIONS}

\author{
Milana Krnajac, Fakultet tehničkih nauka, Novi Sad
}

\begin{abstract}
Oblast - PROJEKTOVANJE I ORGANIZACIJA
Kratak sadržaj - U radu su prikazani rezultati istraživanja na raskrsnicama Bulevara cara Lazara sa Bulevarom oslobođenja $i$ Fruškogorskom ulicom $u$ Novom Sadu, u cilju analize uticaja izgradnje TC Promenada na saobraćaj $i$ analize troškova goriva $i$ zagađenja pri zaustavljanju vozila na tim raskrsnicama.
\end{abstract}

Ključne reči: Signalisane raskrsnice, Procena uticaja na saobraćaj

\begin{abstract}
The paper presents research performed at the intersections of Emperor Lazar Boulevard with Liberation Boulevard and Fruškogorska street in Novi Sad. The aim of the research was the impact analysis of SC Promenada on the traffic flow at these intersections and analyses of fuel costs and pollution when vehicles stop at the intersections.
\end{abstract}

Keywords: Signalized intersections, Traffic impact assessment

\section{UVOD}

Činjenica je da u Srbiji raste broj registrovanih automobila po glavi stanovnika, i da su kraća putovanja sve više zastupljena, zbog čega se javljaju veći zahtevi za protokom. To za posledicu ima gužve na saobraćajnoj mreži, veće vremenske gubitke, vreme putovanja, potrošnju goriva, emisiju štetnih gasova, nivo buke, i drugo.

Zbog toga je važno planiranje i dobra organizacija korištenja saobraćajne mreže, kao i pravovremena analiza uticaja razvoja okruženja na saobraćaj. Raskrsnice su mesta ukrštanja saobraćajnih tokova i usko grlo na saobraćajnoj mreži. Da bi se smanjili negativni uticaji raskrsnica na uslove odvijanja saobraćaja, potrebno je vršiti istraživanja pomoću kojih se mogu utvrditi mere za poboljšanje tih uslova, kao i vršiti primenu istih.

Ovaj rad se bazira na rezultatima istraživanja odvijanja saobraćaja u 2015. i 2020. godini na dve raskrsnice u Novom Sadu, i to:

- raskrsnica R1 (Bulevar cara Lazara - Bulevar oslobođenja);

- raskrsnica R2 (Bulevar cara Lazara - Fruškogorska ulica).

\footnotetext{
NAPOMENA:

Ovaj rad proistekao je iz master rada čiji mentor je bio dr Nenad Ruškić, vanr. prof.
}

U decembru 2018. godine, između te dve raskrsnice, izgrađen je TC Promenada koji je izazvao određene promene zahteva za protokom. Upravo zbog toga, osnovni zadatak ovog rada je ispitivanje uticaja TC Promenada na uslove odvijanja saobraćaja na analiziranim raskrsnicama, kao i na troškove goriva i zagađenja pri zaustavljanju vozila na istim.

\section{TEORIJSKE OSNOVE}

U ovom poglavlju je detaljnije objašnjen pojam Traffic Impact Assessment - TIA, kao i važnost sprovođenja ove analize. Takođe je opisan glavni zadatak TIA analize i način sprovođenja.

\subsection{Procena uticaja na saobraćaj - TIA}

Intenziviranjem urbanog razvoja i smanjenjem javnih resursa, procena uticaja razvoja okruženja na saobraćaj postaje važno sredstvo za planiranje. Zbog toga, projekti urbanog razvoja zahtevaju sveobuhvatnu procenu uticaja na saobraćaj, poznatu pod pojmom TIA - Traffic Impact Assessment. TIA omogućava da se utvrdi da li će saobraćajna mreža biti u stanju da zadovolji nove zahteve za protokom, izazvane predloženim razvojem, naročito $\mathrm{u}$ kratkom roku, kao i procenu olakšavajućih mera za minimiziranje uticaja razvoja. Pored uticaja na saobraćaj, TIA razmatra i uticaje na sve korisnike saobraćaja (uključujući pešake, bicikliste i korisnike javnog prevoza), na poslovanje, i na saobraćajnu infrastrukturu.

Kako bi se izvršila precizna analiza i procena uticaja na saobraćaj, neophodno je imati pristup sledećim podacima:

- trenutno stanje saobraćaja;

- detalji razvoja;

- metode koje se koriste za procenu generisanja saobraćaja i podaci o generisanju saobraćaja;

- raspodela saobraćaja po području i podaci o obimu saobraćaja;

- procena rizika bezbednosti u saobraćaju;

- procena uticaja na javni prevoz;

- procena uticaja na pešake i bicikliste;

- raspored raskrsnica i podaci o fazama signala;

- detalji o svim dodatnim radovima na saobraćajnoj infrastrukturi, koji su sprovedeni u cilju ublažavanja uticaja razvoja na saobraćaj;

- kratak prikaz predloženih građevinskih radova kao dela razvoja [1].

Analiza i procena uticaja na saobraćaj se sprovodi prema sledećim koracima:

- definisanje područja uticaja; 
- karakter osnovnog saobraćajnog toka;

- procena generisanja saobraćaja;

- izrada plana upravljanja saobraćajem;

- pristupne tačke i analiza usmeravanja saobraćaja;

- analiza potreba za parkiranjem;

- formulisanje mehanizama za primenu preporučenih mera [2].

\section{ANALIZA POSTOJEĆEG STANJA}

Analizirane raskrsnice nalaze se u južnom delu Novog Sada. S obzirom na blizinu centra i univerzitetskog kampusa, može se reći da se nalaze u zoni koja privlači veliki broj putovanja.

Pored toga, povezuju Most slobode sa železničkom i glavnom autobuskom stanicom, što znači da su u veoma prometnoj zoni, jer Most slobode na neki način predstavlja ulaz/izlaz iz grada. Postoje dva prilaza prema TC Promenada, i to:

- južni - sa Bulevara cara Lazara;

- zapadni - sa Bulevara oslobođenja (slika 1.).

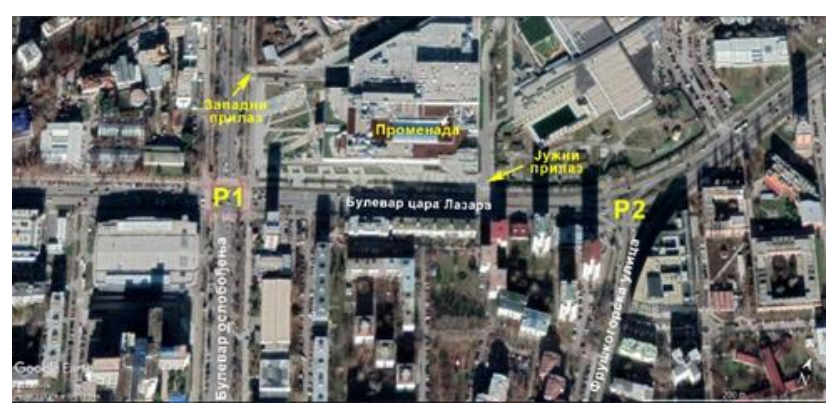

Slika 1. Položaj prilaza prema TC Promenada [3]

\subsection{Karakteristike raskrsnice R1 (Bulevar cara Lazara - Bulevar oslobođenja)}

Raskrsnica R1 je standardna četvorokraka signalisana raskrsnica u nivou (slika 2.).

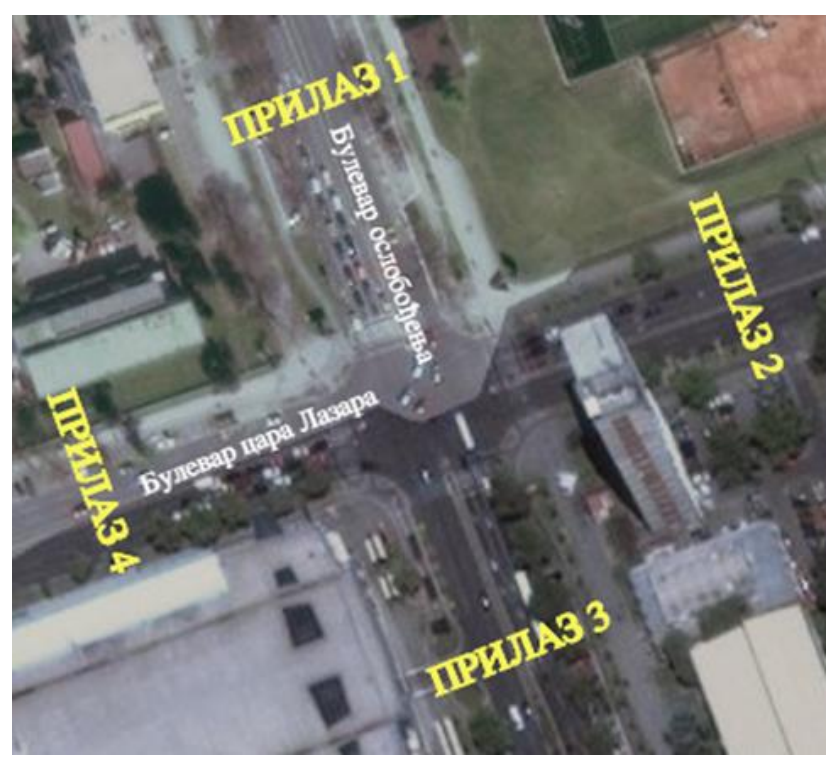

Slika 2. Izgled raskrsnice R1 [4]

\subsection{Karakteristike raskrsnice $\mathbf{R 2}$ (Bulevar cara Lazara - Fruškogorska ulica)}

Raskrsnica R2 je nestandardna trokraka signalisana raskrsnica u nivou (slika 3.).

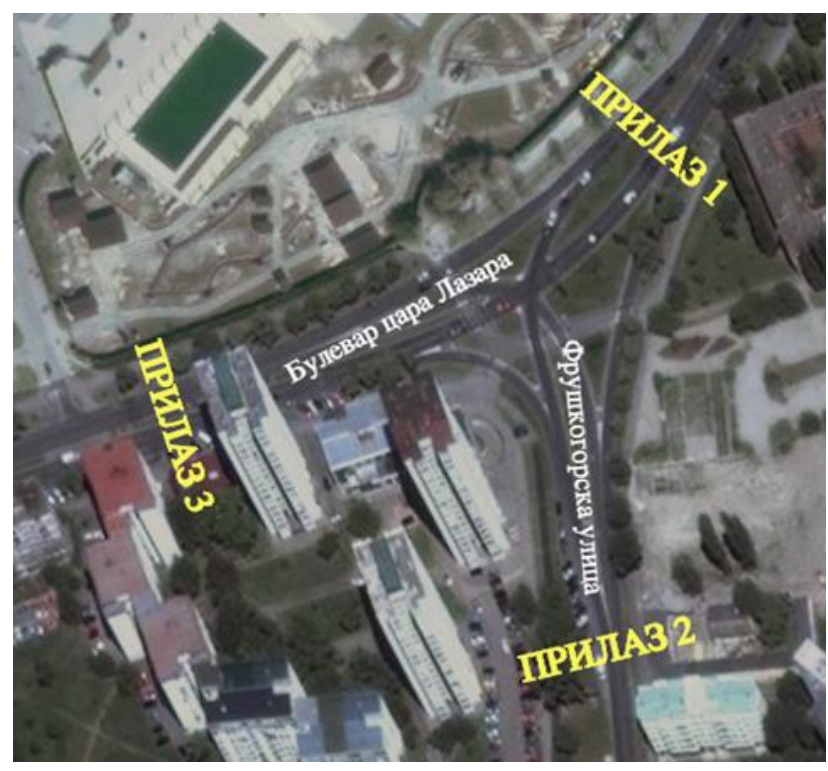

Slika 3. Izgled raskrsnice $R 2$ [4]

\section{ANALIZA SAOBRAĆAJNOG TOKA}

U cilju utvrđivanja karakteristika saobraćajnog toka, izvršeno je brojanje saobraćaja, čime su dobijeni podaci o veličini toka, njegovoj strukturi i distribuciji po smerovima. Na obe raskrsnice je izvršeno kontrolno brojanje u četvrtak 25.06.2020. godine, na R1 od 15:00 do 16:00 časova, a na R2 od 16:00 do 17:00 časova. Dobijene vrednosti protoka vozila su zatim ekspandovane na osnovu postojećeg 24-časovnog brojanja iz 2019. godine.

Evidentiranje podataka na obe raskrsnice je izvršeno po 15-minutnim intervalima i prema kategorijama vozila. Analizom je utvrđeno da se vršni čas na raskrsnici R1 javlja u vremenskom intervalu od 15:00 do 16:00 časova, a na raskrsnici R2 od 16:00 do 17:00 časova. Na obe raskrsnice je zastupljen složen i nehomogen saobraćajni tok, i vladaju povremeno prekinuti uslovi odvijanja saobraćaja.

\subsection{Rezultati istraživanja iz 2015. godine}

Prema rezultatima istraživanja iz 2015. godine, na raskrsnici R1 ukupno saobraćajno opterećenje u periodu od 24 časa je iznosilo 78.045 vozila, a najopterećeniji period je bio popodnevni vršni period. Najveći intenzitet toka je zabeležen u periodu od 15:00 do 16:00 časova (5.001 vozilo). Analiza distribucije saobraćajnog toka po prilazima u vršnom času pokazuje da je prilaz 2 (istočni) bio najopterećeniji (1.607 vozila), a prilaz 4 (zapadni) najmanje opterećen (983 vozila). Vremenski gubici u vršnom času su izračunati pomoću softverskog programa Synchro na obe raskrsnice. Prosečni vremenski gubici na raskrsnici R1 u vršnom času su iznosili 56 sekundi po vozilu. Na prilazu 3 (južni) su se javljali najveći vremenski gubici (70 sekundi po vozilu), a na prilazu 1 (severni) najmanji (39,8 sekundi po vozilu).

$\mathrm{Na}$ raskrsnici R2 najopterećeniji period je bio prepodnevni vršni period, a najveći intenzitet toka je zabeležen u periodu od 08:00 do 09:00 časova (2.844 vozila). Analiza distribucije saobraćajnog toka po prilazima u vršnom času pokazuje da je prilaz 3 (zapadni) bio najopterećeniji (1.584 vozila), a prilaz 2 (južni) najmanje opterećen (447 vozila). Prosečni vremenski gubici na raskrsnici R2 u 
vršnom času su iznosili 26,4 sekunde po vozilu. Na prilazu 1 (istočni) su se javljali najveći vremenski gubici (30,7 sekundi po vozilu), a na prilazu 3 (zapadni) najmanji (17,8 sekundi po vozilu).

\subsection{Rezultati istraživanja iz 2020. godine}

Prema rezultatima istraživanja iz 2020. godine, na raskrsnici R1 ukupno saobraćajno opterećenje u periodu od 24 časa je iznosilo 84.584 vozila, a najopterećeniji period je bio popodnevni vršni period. Najveći intenzitet toka je zabeležen u periodu od 15:00 do 16:00 časova (5420 vozila). Analizom strukture saobraćajnog toka na raskrsnici R1, utvrđeno je da su najviše zastupljeni putnički automobili $(96,8 \%)$, zatim autobusi $(1,4 \%)$, laka i srednja teretna vozila $(0,9 \%)$ i najmanje motocikli $(0,8 \%)$.

Teška teretna vozila nisu zastupljena $u$ saobraćajnom toku, jer je u ovoj zoni zabranjeno njihovo kretanje. Analiza distribucije saobraćajnog toka po prilazima $u$ vršnom času pokazuje da je prilaz 3 (južni) najopterećeniji (1.751 vozilo), a prilaz 4 (zapadni) najmanje opterećen (1.091 vozilo). Prosečni vremenski gubici na raskrsnici R1 u vršnom času iznose 70,4 sekunde po vozilu. Na prilazu 3 (južni) se javljaju najveći vremenski gubici (119,7 sekundi po vozilu), a na prilazu 2 (istočni) najmanji (35 sekundi po vozilu).

Na raskrsnici R2 najopterećeniji period je bio popodnevni vršni period. Najveći intenzitet toka je zabeležen u periodu od 16:00 do 17:00 časova (2.965 vozila). Analizom strukture saobraćajnog toka na raskrsnici R2, utvrđeno je da su najviše zastupljeni putnički automobili $(95,5 \%)$, zatim autobusi $(2,1 \%)$, laka i srednja teretna vozila $(1,6 \%)$ i najmanje motocikli $(0,8 \%)$.

Teška teretna vozila nisu zastupljena u saobraćajnom toku, jer je u ovoj zoni zabranjeno njihovo kretanje. Analiza distribucije saobraćajnog toka po prilazima $\mathrm{u}$ vršnom času pokazuje da je prilaz 1 (istočni) najopterećeniji (1534 vozila), a prilaz 2 (južni) najmanje opterećen (503 vozila). Prosečni vremenski gubici na raskrsnici R2 u vršnom času iznose 30,1 sekund po vozilu. Na prilazu 2 (južni) se javljaju najveći vremenski gubici (101,4 sekunde po vozilu), a na prilazu 1 (istočni) najmanji (12,6 sekundi po vozilu).

\section{ANALIZA UTICAJA IZGRADNJE TRŽNOG CENTRA PROMENADA NA SAOBRAĆAJ}

Svaka promena i razvoj okruženja, na neki način, ima uticaj i na promenu saobraćaja u tom okruženju. Vodeći se tim stavom, u ovom radu se, na osnovu poređenja karakteristika odvijanja saobraćaja pre i posle izgradnje TC Promenada, ispituje njen uticaj na saobraćaj $u$ tom okruženju. Konkretno su analizirane dve raskrsnice koje se nalaze u neposrednoj blizini, i koje predstavljaju područje uticaja.

\subsection{Analiza uticaja TC Pomenada na saobraćaj na raskrsnici $\mathbf{R} 1$}

Poređenjem rezultata istraživanja iz 2015. i 2020. godine ustanovljeno je povećanje intenziteta saobraćajnog toka u vršnom času posle izgradnje TC Promenada, odnosno broj vozila na ovoj raskrsnici se povećao sa 5001 na 5420 vozila. To je uticalo i na povećanje vremenskih gubitaka po vozilu, koji su povećani sa 56 na 70,4 sekunde po vozilu. Poređenjem rezultata iz 2015. i 2020. godine je utvrđeno da su intenzitet toka i vremenski gubici na prilazu 3 (južni) povećani, dok su na ostalim prilazima ostali približno jednaki. Analizom distribucije protoka vozila po smerovima kretanja je utvrđeno da su se intenzitet toka i vremenski gubici najviše povećali iz pravca Mosta slobode, odnosno na prilazu 3 (južni) za sve smerove kretanja, dok je na ostalim prilazima uočeno povećanje samo za smerove kretanja ka TC Promenada. Takođe, analizom je utvrđeno da od ukupnog saobraćajnog toka na izlivnom grlu prilaza 1 (severni) na ovoj raskrsnici u vršnom času, $11,7 \%$ vozila se kreće ka TC Promenada zapadnim prilazom.

\subsection{Analiza uticaja TC Pomenada na saobraćaj na raskrsnici $\mathbf{R 2}$}

Poređenjem rezultata istraživanja iz 2015. i 2020. godine ustanovljeno je povećanje intenziteta saobraćajnog toka u vršnom času posle izgradnje TC Promenada, odnosno broj vozila na ovoj raskrsnici se povećao sa 2772 na 2965 vozila. To je uticalo i na povećanje vremenskih gubitaka po vozilu, koji su povećani sa 26,4 na 30,1 sekund po vozilu. Poređenjem rezultata iz 2015. i 2020. godine utvrđeno je da je intenzitet toka na prilazu 1 (istočni) povećan, a vremenski gubici su povećani na prilazu 2 (južni). Analizom distribucije protoka vozila po smerovima kretanja je utvrđeno da se intenzitet toka povećao iz pravca Univerzitetskog kampusa, odnosno na prilazu 1 (istočni) za smer pravo, zatim na prilazu 3 (zapadni) za sve smerove kretanja, i na prilazu 2 (južni) za smer levo, odnosno ka TC Promenada. Uočeno je povećanje vremenskih gubitaka po vozilu na prilazu 2 (južni) za oba smera kretanja, a posebno za leva skretanja. Dok su za sve ostale smerove kretanja na ovoj raskrsnici vremenski gubici po vozilu ostali približno jednaki. Takođe, analizom je utvrđeno da od ukupnog saobraćajnog toka na izlivnom grlu prilaza 3 (zapadni) na ovoj raskrsnici u vršnom času, 9,1\% vozila se kreće ka TC Promenada južnim prilazom.

\section{ANALIZA TROŠKOVA GORIVA I ZAGAĐENJA PRI ZAUSTAVLJANJU VOZILA}

Pored uticaja TC Promenada na saobraćaj, neophodno je ispitati i njen uticaj na troškove nastale u saobraćaju na tim raskrsnicama.

\subsection{Analiza troškova goriva i zagađenja pri zaustavljanju vozila na raskrsnici $R 1$}

Troškovi goriva i zagađenja su analizirani u vršnom času, vanvršnim časovima, kao i ukupni dnevni i godišnji troškovi. Rezultati su prikazani po raskrsnici, prilazima, vrsti pogonskog goriva, i vrsti izduvnih gasova. U analizi troškova goriva pri zaustavljanju vozila korišteni su podaci o:

- protoku;

- vremenskim gubicima po vozilu;

- prosečnoj potrošnji goriva dok je vozilo zaustavljeno;

- ceni goriva.

Za prosečnu potrošnju goriva dok je vozilo zaustavljeno usvojena je vrednost od $0,85 \mathrm{l} / \mathrm{h}$ po vozilu. U proračunu potrošnje goriva nije uzeta $u$ obzir potrošnja goriva komercijalnih vozila, jer je njihov procenat učešća u strukturi saobraćajnog toka na obe raskrsnice vrlo mali. 
$\mathrm{Na}$ osnovu izračunatih ukupnih troškova goriva pri zaustavljanju vozila po časovima, određeni su ukupni dnevni troškovi, koji su iznosili 1025,00 €/dan u 2015. godini, a u 2020. iznose 1396,57 €/dan. Nakon toga su određeni i ukupni godišnji troškovi goriva pri zaustavljanju vozila, koji su iznosili 374.123,99€ u 2015. godini, a u 2020. iznose 509.749,63 €. Poređenjem rezultata analize ukupnih godišnjih troškova goriva pri zaustavljanju vozila na raskrsnici R1 pre i posle izgradnje TC Promenada utvrđeno je povećanje ukupnih troškova u 2020. godini.

U analizi troškova zagađenja pri zaustavljanju vozila korišteni su podaci o:

- protoku;

- vremenskim gubicima po vozilu;

- prosečnoj potrošnji goriva dok je vozilo zaustavljeno;

- emisiji štetnih gasova;

- ceni emisije štetnih gasova.

$\mathrm{U}$ radu su posmatrane tri štetne materije iz izduvnih gasova, i to: $\mathrm{CO}_{2}, \mathrm{~N}_{2} \mathrm{O}$ i $\mathrm{CH}_{4}$. Na osnovu izračunatih ukupnih časovnih i dnevnih troškova zagađenja pri zaustavljanju vozila na ovoj raskrsnici, određeni su ukupni godišnji troškovi zagađenja pri zaustavljanju vozila koji su za emisiju $\mathrm{CO}_{2}$ povećani sa $2.426,80$ $€ /$ godini na $3.306,44$ €/godini; za emisiju N2O sa 49,34 $€ /$ godini na 67,22 €/godini; i za emisiju $\mathrm{CH} 4$ sa 56,54 $€ /$ godini na $77,04 € /$ godini. Poređenjem rezultata analize ukupnih godišnjih troškova zagađenja pri zaustavljanju vozila na raskrsnici R1 pre i posle izgradnje TC Promenada, za svaku od posmatranih emisija štetnih gasova i vrste pogonskog goriva, utvrđeno je povećanje ukupnih troškova u 2020. godini.

\subsection{Analiza troškova goriva i zagađenja pri zaustavljanju vozila na raskrsnici $R 2$}

Analiza troškova goriva i zagađenja pri zaustavljanju vozila na raskrsnici R2 je izvršena na isti način kao i na raskrsnici R1. Prema rezultatima analize, ukupni dnevni troškovi goriva pri zaustavljanju vozila su iznosili 267,80 $€ /$ dan u 2015. godini, a u 2020. iznose 326,63 €/dan. Ukupni godišnji troškovi goriva pri zaustavljanju vozila su iznosili 97.746,16 € u 2015. godini, a u 2020. iznose $119.220,69 €$. Poređenjem rezultata analize ukupnih godišnjih troškova goriva pri zaustavljanju vozila na raskrsnici R2 pre i posle izgradnje TC Promenada utvrđeno je povećanje ukupnih troškova u 2020. godini.

$\mathrm{Na}$ osnovu izračunatih ukupnih časovnih i dnevnih troškova zagađenja pri zaustavljanju vozila na ovoj raskrsnici, određeni su ukupni godišnji troškovi zagađenja pri zaustavljanju vozila koji su za emisiju $\mathrm{CO}_{2}$ povećani sa $634,14 € /$ godini na $773,36 € /$ godini; za emisiju N2O sa $12,89 € /$ godini na $15,72 € /$ godini; i za emisiju $\mathrm{CH} 4$ sa $14,78 € /$ godini na $18,02 € /$ godini. Poređenjem rezultata analize ukupnih godišnjih troškova zagađenja pri zaustavljanju vozila na raskrsnici R2 pre i posle izgradnje TC Promenada, za svaku od posmatranih emisija štetnih gasova i vrste pogonskog goriva, utvrđeno je povećanje ukupnih troškova u 2020. godini.

\section{ZAKLJUČAK}

Tržni centri predstavljaju objekte privlačenja putovanja, što dovodi do očekivanog porasta intenziteta saobraćajnog toka na okolnim saobraćajnicama. Pored toga, očekivano je i povećanje intenziteta toka za manevre skretanja ka objektu na raskrsnicama u njegovoj neposrednoj blizini. Zbog toga je važno ispitati uticaj takvih objekata na odvijanje saobraćaja u okolini, a oblast koja se time bavi naziva se TIA - Traffic Impact Assessment. TIA omogućava da se utvrdi da li će saobraćajna mreža biti u stanju da zadovolji nove zahteve za protokom, izazvane izgradnjom ovakvih objekata, a istovremeno omogućava i procenu mera za minimiziranje njihovog uticaja na saobraćaj.

U ovom radu je analiziran uticaj izgradnje TC Promenada na saobraćaj. Područje uticaja predstavljaju dve raskrsnice, koje su u ovom radu i posmatrane. Prvo je izvršena analiza postojećeg stanja, a u tu svrhu je izvršeno istraživanje na posmatranim raskrsnicama, koje je obuhvatalo brojanje saobraćaja. Na osnovu toga su dobijeni podaci o protocima vozila po prilazima i smerovima kretanja, ukupan protok vozila na raskrsnicama, utvrđen je vršni čas, kao i struktura saobraćajnog toka. Zatim su, pomoću softverskog programa Synchro, dobijeni vremenski gubici po vozilu u vršnom času. Svi dobijeni podaci postojećeg stanja na analiziranim raskrsnicama, su upoređeni sa rezultatima istraživanja koje je sprovedeno pre izgradnje TC Promenada. Daljom analizom je ustanovljeno da je na obe raskrsnice u 2020. godini (posle izgradnje TC Promenada) povećan intenzitet saobraćajnog toka i vremenski gubici, u odnosu na 2015. godinu (pre izgradnje TC Promenada). Analizom je ustanovljeno povećanje ukupne potrošnje goriva, pa samim tim i ukupne emisije štetnih gasova pri zaustavljanju vozila na ovim raskrsnicama. A rezultati analize troškova pokazuju da su povećani ukupni troškovi goriva i zagađenja emisijom štetnih materija iz izduvnih gasova pri zaustavljanju vozila na obe raskrsnice. Kako bi se preciznije sagledao uticaj TC Promenada na saobraćaj na ovim raskrsnicama, posmatrana su i dva prilaza prema TC Promenada - južni (iz pravca raskrsnice R2) i zapadni (iz pravca raskrsnice R1). Rezultati su pokazali da $9,1 \%$ vozila, od ukupnog saobraćajnog toka na tom pravcu, ide ka TC Promenada južnim prilazom, dok na zapadnom prilazu ta vrednost iznosi 11,7\%. Prema tome, može se zaključiti da TC Promenada ima uticaj na odvijanje saobraćaja na ovim raskrsnicama. Može se reći da je taj uticaj negativan sa ekonomskog, ekološkog i funkcionalnog aspekta.

\section{LITERATURA}

[1] https://www.ebtraffic.com.au

[2] J. Regidor, R. Teodoro, "Traffic Impact Assessment for Sustainable Traffic Management and

Transportation Planning in Urban Areas", University of Philippines Diliman, Quezon City, 2005.

[3] https://earth.google.com

[4] https://geosrbija.rs

\section{Kratka biografija:}

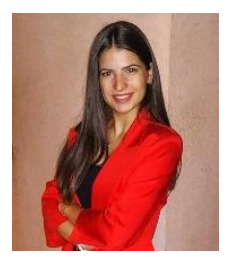

Milana Krnajac je rođena u Novom Sadu 1996. godine. Osnovne akademske studije iz oblasti Saobraćaj i transport završila je na Fakultetu tehničkih nauka 2019. godine, kada upisuje Master akademske studije iz oblasti Projektovanje i organizacija. Kontakt: milana.krnajac@gmail.com 